\title{
Nitric oxide precursors and congenital heart surgery: A randomized controlled trial of oral citrulline
}

Heidi A.B. Smith, MD, MSCl, ${ }^{a}$ Jeffrey A. Canter, MD, MPH, ${ }^{b}$ Karla G. Christian, MD, ${ }^{c}$ Davis C. Drinkwater, MD, ${ }^{c}$ Frank G. Scholl, MD, ${ }^{\mathrm{c}}$ Brian W. Christman, MD, ${ }^{\mathrm{d}}$ Geraldine D. Rice, RN, BSN, ${ }^{a}$ Frederick E. Barr, MD, MSCI, ${ }^{a}$ and Marshall L. Summar, MDa

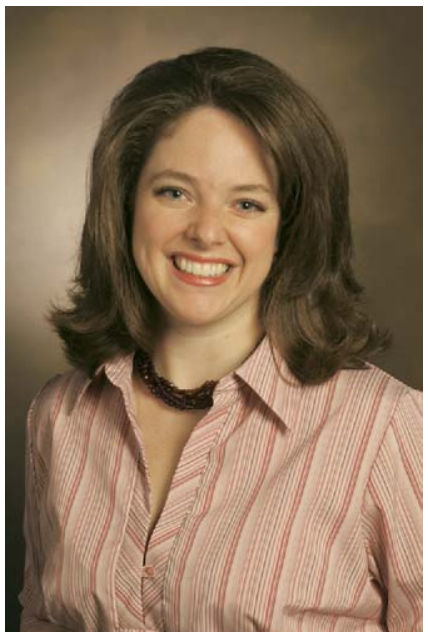

Dr Smith

From the Departments of Pediatrics, ${ }^{\mathrm{a}}$ Cardiothoracic Surgery, ${ }^{\mathrm{c}}$ and Medicine, ${ }^{\mathrm{d}}$ and Center for Human Genetics Research, Vanderbilt University Medical Center, ${ }^{\mathrm{b}}$ Nashville, Tenn.

Supported by National Institutes of Health Funded (K12) Vanderbilt Clinical Research Scholars Program Grant K12 RR17697 (H.A.B.S.), NIH5RO14273317 (F.E.B.), and Vanderbilt Turner's Scholar Program (F.E.B.)

Received for publication Aug 15, 2005; accepted for publication Feb 13, 2006.

Address for reprints: Heidi A. Beverley Smith, MD, MSCI, 5121 Doctor's Office Tower, Nashville, TN 37232-9075 (E-mail: heidi.smith@vanderbilt.edu).

J Thorac Cardiovasc Surg 2006;132:58-65

$0022-5223 / \$ 32.00$

Copyright (C) 2006 by The American Association for Thoracic Surgery

doi:10.1016/j.jtcvs.2006.02.012
Objective: The study sought to determine whether citrulline supplementation, a precursor to nitric oxide synthesis, is safe and efficacious in increasing plasma citrulline concentrations and decreasing the risk of postoperative pulmonary hypertension.

Study Design: Forty children, undergoing cardiopulmonary bypass and at risk for pulmonary hypertension, were randomized to receive 5 perioperative doses (1.9 $\mathrm{g} / \mathrm{m}^{2}$ per dose) of either oral citrulline or placebo. Plasma citrulline and arginine concentrations were measured at 5 time points. Measurements of systemic blood pressure and presence of pulmonary hypertension were collected.

Results: Median citrulline concentrations were significantly higher in the citrulline group versus the placebo group immediately postoperatively $(36 \mu \mathrm{mol} / \mathrm{L}$ vs 26 $\mu \mathrm{mol} / \mathrm{L}, P=.012)$ and at 12 hours postoperatively $(37 \mu \mathrm{mol} / \mathrm{L}$ vs $20 \mu \mathrm{mol} / \mathrm{L}, P=$ .015). Mean plasma arginine concentrations were significantly higher in the citrulline group versus the placebo group by 12 hours postoperatively $(36 \mu \mathrm{mol} / \mathrm{L}$ vs 23 $\mu \mathrm{mol} / \mathrm{L}, P=.037)$. Mean systemic blood pressure did not differ between groups $(P=$ .53). Postoperative pulmonary hypertension developed in 9 patients, 6 of $20(30 \%)$ in the placebo group and 3 of $20(15 \%)$ in the citrulline group $(P=.451)$, all of whom had plasma citrulline concentrations less than age-specific norms. Postoperative pulmonary hypertension did not develop in patients who demonstrated plasma citrulline concentrations in excess of $37 \mu \mathrm{mol} / \mathrm{L}(P=.036)$.

Conclusions: Oral citrulline supplementation safely increased plasma citrulline and arginine concentrations compared with placebo after cardiopulmonary bypass. Postoperative pulmonary hypertension did not occur in children with naturally elevated citrulline levels or elevations through supplementation. Oral citrulline supplementation may be effective in reducing postoperative pulmonary hypertension.

$\mathrm{P}$ ulmonary hypertension is a potentially severe complication after congenital heart surgery that can lead to right-ventricular failure, reduced cardiac output, and death. ${ }^{1}$ Treatment options include oxygen administration, induced alkalosis, sedation, paralysis, inotropic support, and parenteral or inhaled vasodilators. ${ }^{2}$

Nitric oxide (NO) causes cyclic guanosine monophosphate-mediated vasodilation of the pulmonary vasculature. Endogenous NO is produced from the metabolism of citrulline and L-arginine, amino acids generated by the urea cycle (Figure 1). ${ }^{3}$ Cardiopulmonary bypass leads to significant reductions in postoperative concentrations of citrulline and arginine, ${ }^{4}$ and dysfunction of the pulmonary endothelium., ${ }^{5,6}$

Intravenous L-arginine has been shown to reduce both pulmonary and systemic pressures. $^{5,7}$ This global response would not be tolerated in patients after cardiac surgery, who are already prone to low cardiac output states. The maintenance of high plasma arginine concentrations is also problematic because of poor bioavail- 


\section{Abbreviations and Acronyms \\ $\mathrm{IQR}=$ interquartile range \\ $\mathrm{NO}=$ nitric oxide \\ PCCU $=$ pediatric critical care unit}

ability and swift metabolism by intestinal and cytosolic arginase. $^{8}$ In contrast, administration of oral citrulline is more effective in maintaining plasma L-arginine concentrations than administration of arginine in healthy volunteers. ${ }^{9}$ Citrulline has no recognized toxicity and is used as replacement therapy for children with urea cycle defects.

The purpose of this study is to determine whether perioperative oral citrulline supplementation is (1) safe in patients after heart surgery, (2) efficacious in increasing plasma citrulline and arginine concentrations, and (3) associated with development of postoperative pulmonary hypertension.

\section{Methods}

\section{Patient Enrollment}

Vanderbilt Institutional Review Board approval was obtained before patient enrollment. Forty patients were prospectively enrolled in this randomized, placebo-controlled, doubled-blinded study at Vanderbilt Children's Hospital between April 2003 and September 2004.

All infants or children less than 6 years of age undergoing 1 of 6 surgical procedures for correction of congenital heart lesions were eligible for enrollment. Procedures included (1) ventricular septal defect repair, (2) atrioventricular septal defect repair, (3) bidirectional Glenn procedure, (4) modified Fontan procedure, (5) Norwood I procedure with right ventricle to pulmonary artery conduit for hypoplastic left heart syndrome, and (5) arterial switch procedure for transposition of the great arteries. Exclusion criteria included (1) significant pulmonary artery narrowing not addressed surgically, (2) previous pulmonary artery stent placement, (3) previous pulmonary artery angioplasty, (4) significant left-sided atrioventricular valve regurgitation, (5) pulmonary venous return abnormalities, and (6) pulmonary vein stenosis.

Informed written consent was obtained from parents at the preoperative evaluation. One of 3 cardiac surgeons at Vanderbilt Children's Hospital performed the surgical procedures using similar cardiopulmonary bypass and cardioplegia preparations.

Pulmonary hypertension was defined as mean pulmonary arterial pressures of at least $25 \mathrm{~mm} \mathrm{Hg}$ or exceeding $50 \%$ of the mean systemic artery pressure. ${ }^{10,11}$

Pulmonary pressures were also estimated by Doppler echocardiography with the following diagnostic criteria: (1) significant tricuspid regurgitation, (2) enlarged or hypertrophied right ventricle without evidence of pulmonary stenosis, or (3) intraventricular septal flattening. ${ }^{12,13}$

All patients underwent perioperative and postoperative transesophageal echocardiograms per cardiac intensive care protocol. In addition, patients without direct pulmonary arterial monitoring underwent subsequent echocardiograms in the 48-hour postoperative period when clinically indicated for pulmonary hypertension.

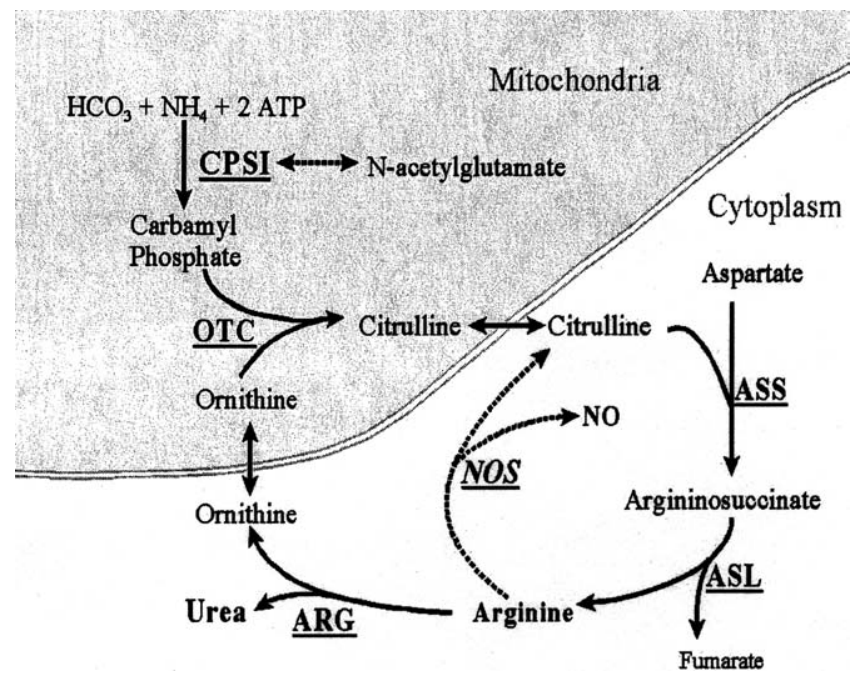

Figure 1. Urea cycle enzymes are differentially found in 2 compartments: the mitochondria of hepatocytes and the cytosol of all cells. Citrulline easily moves across cellular membranes. Once within the cytosol, citrulline is metabolized into L-arginine, which is then metabolized either by arginase into urea or by nitric oxide synthetase into NO. ATP, Adenosine triphosphate; CPSI, carbamoyl phosphate synthetase I; OTC, ornithine transcarbamylase; $A R G$, arginine; NOS, nitric oxide synthetase; NO, nitric oxide; $A S S$, argininosuccinate synthetase; $A S L$, argininosuccinate lyase.

Echocardiograms were not obtained for pulmonary pressure determination in patients undergoing the modified Fontan or bidirectional Glenn procedures. Perioperative or postoperative transesophageal or transthoracic echocardiograms were interpreted by pediatric cardiologists at Vanderbilt Children's Hospital.

Physicians, nursing staff, and patients/families were blinded to treatment arm assignments. Clinical data and patient demographics were obtained from medical records before knowledge of study results.

\section{Adverse Event}

Systemic blood pressure was monitored continuously during the 48-hour study period because of the theoretic risk of hypotension associated with citrulline administration. An adverse event was defined as a greater than $25 \%$ decrease in systemic mean blood pressure from baseline (measured before cardiopulmonary bypass). Hypotensive patients were treated with volume resuscitation and/or pharmacologic support. Patients were not withdrawn from the study unless hypotension was unresponsive to interventions.

\section{Study Protocol}

Forty patients were randomized to receive either placebo or citrulline perioperatively. Randomization was performed by the Investigational Drug Service of the Vanderbilt Hospital Clinical Pharmacy using computer-generated random numbers in permuted blocks of 4. Patients were enrolled with the intention-to-treat model. 
Citrulline was administered as a $100 \mathrm{mg} / \mathrm{mL}(10 \%)$ solution with distilled water as a suspending agent. The drug and placebo were mixed and distributed by the Investigational Drug Service. Citrulline and placebo were matched for volume and color. Citrulline was administered in 5 doses of $1.9 \mathrm{~g} / \mathrm{m}^{2}$ given every 12 hours for a daily dose of $3.8 \mathrm{~g} / \mathrm{m}^{2}$ and for a total dose of $9.5 \mathrm{~g} / \mathrm{m}^{2}$. This dose was determined by current citrulline replacement therapy for infants and children with urea cycle defects. ${ }^{14,15}$

The first dose of placebo/citrulline was administered through an orogastric feeding tube placed by the research nurse or physician after induction of anesthesia and intubation but before cardiopulmonary bypass in the operating room. The second dose was given immediately on arrival in the pediatric critical care unit (PCCU) for recovery. The third, fourth, and fifth doses were administered at 12,24 , and 36 hours postoperatively in the PCCU, respectively. Postoperative doses were given enterally through a nasogastric feeding tube positioned by the bedside nurse in the PCCU, or by mouth once the patient was extubated.

\section{Sample Collection}

Three milliliters of blood were obtained from each patient at 5 time points: immediately before and after bypass, and at 12,24 , and 48 hours postoperatively. The preoperative blood sample was collected after both anesthetic induction and placement of an arterial or a central venous catheter but before surgical incision and study drug administration. The immediate postoperative sample was collected on arrival in the PCCU, and subsequent samples were collected at respective time intervals and before study drug administration. Samples were collected in citrated tubes, placed on ice, and stored at $4^{\circ} \mathrm{C}$ until processing. Samples were centrifuged within 3 hours of collection for separation of plasma and cellular components. Plasma samples were frozen at $-70^{\circ} \mathrm{C}$ until further laboratory analysis.

Patients were monitored in the PCCU during drug administration and blood collection up to 48 hours postoperatively. If patients had successful recovery before 48 hours with transfer out of the PCCU, central and arterial lines were removed, and therefore drug administration and blood collection were concluded.

\section{Laboratory Measurements}

Concentrations of plasma citrulline, arginine, and all other amino acids were determined by amino-acid analysis on protein-free extracts. Amino acids were separated by cation-exchange chromatography using a Hitachi L8800 amino acid analyzer (Hitachi USA, San Jose, Calif). Calibration of the analyzer was completed before testing of patient samples.

\section{Statistical Analysis}

Continuous outcome variables, when not normally distributed, were reported as medians with interquartile range (IQR). The Shapiro-Wilk test assessed normality. The Mann-Whitney $U$ and Wilcoxon signed-rank tests compared unpaired and paired continuous variables not normally distributed between groups. Dichotomous outcomes for success of randomization and the presence of pulmonary hypertension were reported as proportions and assessed with the Fisher exact test. Parametric testing was used when data were normally distributed and reported as means \pm standard deviation. Analysis of covariance assessed differences between
TABLE 1. Demographic characteristics between groups

\begin{tabular}{|c|c|c|c|}
\hline & $\begin{array}{l}\text { Placebo } \\
(n=20)\end{array}$ & $\begin{array}{l}\text { Citrulline } \\
(\mathrm{n}=20)\end{array}$ & $P$-value \\
\hline Age-months (median, IQR) & $8(4-29)$ & $12(0.3-29)$ & .892 \\
\hline Gender & & & .751 \\
\hline Male & $12(60 \%)$ & $10(50 \%)$ & \\
\hline Female & $8(40 \%)$ & $10(50 \%)$ & \\
\hline Ethnicity & & & 1.000 \\
\hline Caucasian & $18(90 \%)$ & $18(90 \%)$ & \\
\hline Non-Caucasian & $2(10 \%)$ & $2(10 \%)$ & \\
\hline Diagnosis & & & .901 \\
\hline Single ventricle & $11(55 \%)$ & $13(65 \%)$ & \\
\hline VSD/AVSD & $6(30 \%)$ & $4(20 \%)$ & \\
\hline TGA & $3(15 \%)$ & $3(15 \%)$ & \\
\hline Surgery & & & .452 \\
\hline BDG/Fontan & $11(55 \%)$ & $3(15 \%)$ & \\
\hline VSD/AVSD & $6(30 \%)$ & $10(50 \%)$ & \\
\hline Arterial switch & $3(15 \%)$ & $4(20 \%)$ & \\
\hline Norwood & $0(0 \%)$ & $3(15 \%)$ & \\
\hline Trisomy 21 & & & .661 \\
\hline Present & $4(20 \%)$ & $2(10 \%)$ & \\
\hline Absent & $16(80 \%)$ & $18(90 \%)$ & \\
\hline $\begin{array}{l}\text { Bypass time-minutes } \\
\text { (mean } \pm S D)\end{array}$ & $112 \pm 42$ & $121 \pm 47$ & .520 \\
\hline
\end{tabular}

groups in repeated measurements of systemic mean blood pressure. All analyses were 2-sided. Statistical analysis was performed with STATA software, version 8.0 (College Station, Tex).

The power calculation for this study was based on the previously reported mean citrulline concentration of $20.7 \pm 13.0 \mu \mathrm{mol} / \mathrm{L}$ in children after cardiopulmonary bypass. ${ }^{4}$ A sample size of 40 patients equally distributed would have a power $(1-\beta)$ of $87 \%$ to detect a $13 \mu \mathrm{mol} / \mathrm{L}$ ( 1 standard deviation) difference between oral citrulline $(\mathrm{n}=20)$ and placebo $(\mathrm{n}=20)$ using 2-sided significance and an $\alpha=0.05$.

\section{Results}

\section{Patient Enrollment}

Forty patients were randomized to receive citrulline ( $\mathrm{n}=$ $20)$ or placebo $(n=20)$. Baseline characteristics between the 2 groups are shown in Table 1 . The median age of the study population $(\mathrm{N}=40)$ was 8.5 months (IQR 4-29 months); $55 \%$ were male, and $90 \%$ were white. Surgical interventions included ventriculoseptal defect or atrioventricular septal defect repair $(25 \%)$, bidirectional Glenn or Fontan procedures $(53 \%)$, arterial switch repair for transposition of the great arteries (15\%), and Norwood stage I repair $(8 \%)$.

\section{Safety}

Mean blood pressure did not differ between the citrulline and placebo groups $(P=.530)$ (Figure 2). No deaths occurred within the 48-hour study period. Three patients died of postoperative complications within 30 days of surgical re- 


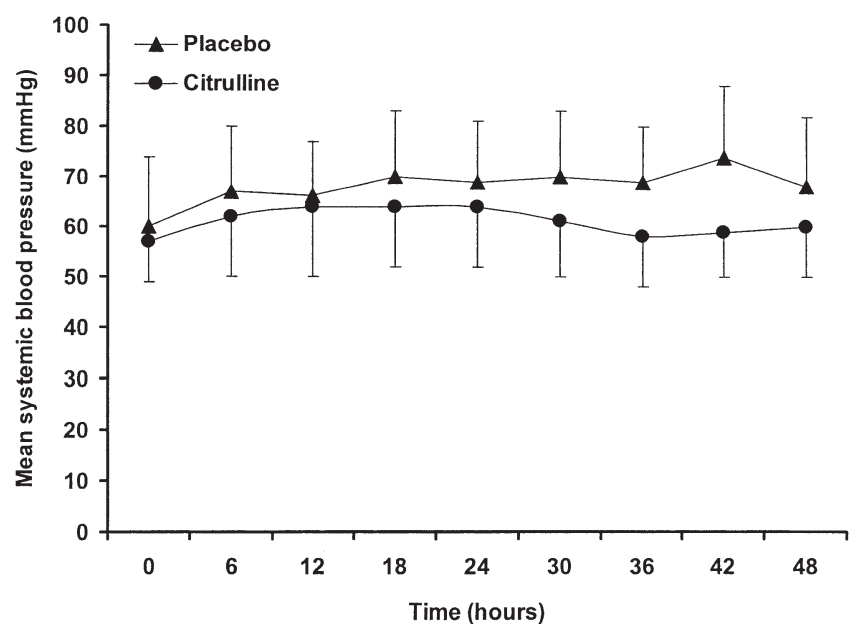

Figure 2. Mean blood pressure did not differ between the oral citrulline and placebo groups $(P=.53$, multivariate analysis of covariance) throughout the 48 -hour study period. Means \pm standard deviation are shown for each group.

pair ( 2 in the citrulline group vs 1 in the placebo group). All deaths were reported to the institutional review board and were found to be unrelated to study drug administration.

All patients $(\mathrm{N}=40)$ completed the study protocol through 12 hours postoperatively. Nine children (4/20 in the citrulline group and 5/20 in the placebo group) successfully recovered by 24 hours postoperatively and transferred out of the PCCU, at which time the study concluded for those individual patients. One patient in the oral citrulline group was withdrawn at 4 hours postoperatively because of complications requiring further surgical intervention, although monitoring continued through 48 hours postoperatively. These patients were represented in all analyses when appropriate through 12 hours postoperatively.

\section{Plasma Citrulline Concentrations}

Median plasma citrulline concentrations were no different between groups at baseline $(P=.355)$. After citrulline supplementation, plasma citrulline concentrations were significantly higher in the oral citrulline group when compared with placebo immediately postoperatively ( $36 \mu \mathrm{mol} / \mathrm{L}$ IQR $28-48 \mu \mathrm{mol} / \mathrm{L}$ vs $26 \mu \mathrm{mol} / \mathrm{L}$ IQR $24-35 \mu \mathrm{mol} / \mathrm{L}, P=.012)$ and 12 hours postoperatively (37 $\mu \mathrm{mol} / \mathrm{L}$ IQR $18-83$ $\mu \mathrm{mol} / \mathrm{L}$ vs $20 \mu \mathrm{mol} / \mathrm{L}$ IQR $15-29 \mu \mathrm{mol} / \mathrm{L}, P=.015)$ (Figure 3). The placebo group demonstrated a significant decrease from baseline in plasma citrulline concentrations after cardiopulmonary bypass immediate postoperatively and 12 hours postoperatively ( $32 \mu \mathrm{mol} / \mathrm{L}$ IQR $25-44$ $\mu \mathrm{mol} / \mathrm{L}$ vs $26 \mu \mathrm{mol} / \mathrm{L}$ and $20 \mu \mathrm{mol} / \mathrm{L}, P=.020$ and $P<$ .001 , respectively). In contrast, the oral citrulline group demonstrated a significant increase from baseline in plasma

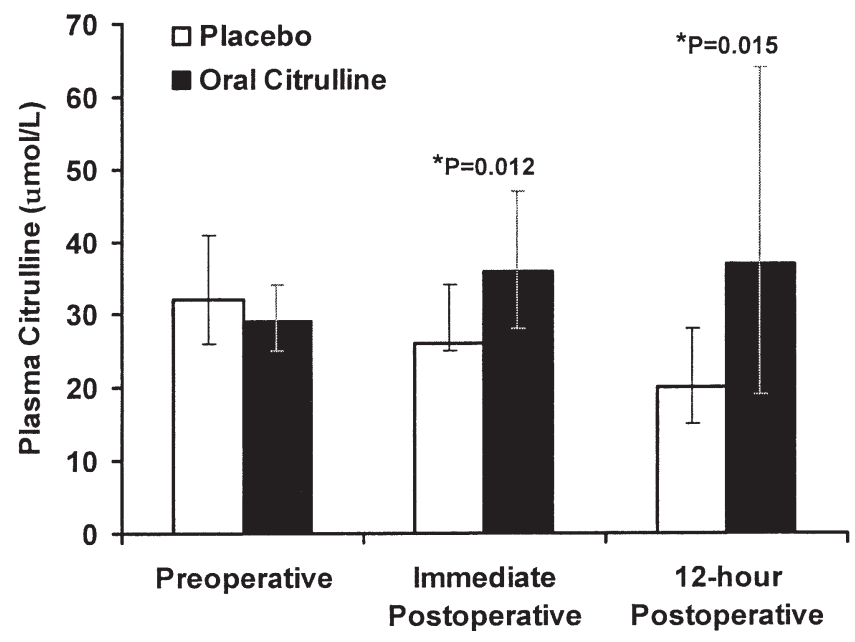

Figure 3. Median plasma citrulline concentrations were significantly higher in the oral citrulline group when compared with the placebo group immediately postoperatively $(P=.012)$ and 12 hours postoperatively $(P=.015)$. The placebo group demonstrated a decrease in citrulline concentrations immediately postoperatively and 12 hours postoperatively $(P=.020, P=.001)$. Medians and $95 \%$ confidence intervals are shown for each group.

citrulline concentrations by 12 hours postoperatively (29

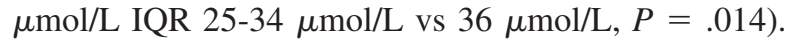

\section{Plasma Arginine Concentrations}

Mean plasma arginine concentrations were no different between groups at baseline $(P=.495)$. After citrulline supplementation, plasma arginine concentrations were significantly higher in the oral citrulline group compared with the placebo group by 12 hours postoperatively ( $36 \pm 24 \mu \mathrm{mol} / \mathrm{L}$ vs $23 \pm$ $13 \mu \mathrm{mol} / \mathrm{L}, P=.037$ ) (Figure 4). The placebo group demonstrated a significant decrease from baseline in plasma arginine concentrations by 12 hours postoperatively ( $38 \mu \mathrm{mol} / \mathrm{L}$ IQR $30-52 \mu \mathrm{mol} / \mathrm{L}$ vs $23 \mu \mathrm{mol} / \mathrm{L}, P<.001)$. In contrast, the oral citrulline group maintained postoperative plasma arginine concentrations at baseline through 12 hours postoperatively (33 $\mu \mathrm{mol} / \mathrm{L}$ IQR $25-54 \mu \mathrm{mol} / \mathrm{L}$ vs $36 \mu \mathrm{mol} / \mathrm{L}, P=.533$ ).

\section{Pulmonary Hypertension}

Twenty-eight patients had direct pulmonary arterial pressure measurements (Table 2), of whom 13 of 28 (46\%) were in the citrulline group. Pulmonary pressures trended lower in the citrulline group compared with placebo immediately postoperatively (18 \pm 5 vs $20 \pm 4, P=.127$ ), 6 hours postoperatively (17 \pm 5 vs $18 \pm 4, P=.290)$, and 12 hours postoperatively ( $17 \pm 6$ vs $17 \pm 5, P=.486)$, although statistical significance could not be demonstrated in this pilot study.

Postoperative pulmonary hypertension developed in 9 patients, 6 of 20 (30\%) in the placebo group and 3 of 20 


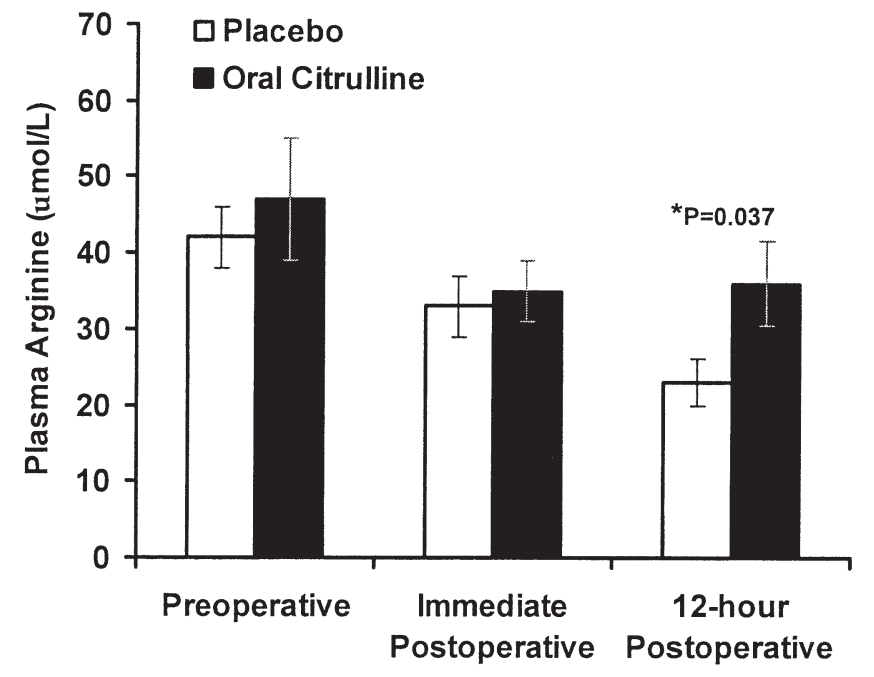

Figure 4. Mean plasma arginine concentrations were significantly higher in the oral citrulline group when compared with the placebo group by 12 hours postoperatively $(P=.037)$. The placebo group demonstrated a decrease in plasma arginine concentrations by 12 hours postoperatively $(P<.001)$. Means and standard error of mean are shown for each group.

(15\%) in the citrulline group $(P=.451)$, all of whom had plasma citrulline concentrations less than age-specific norms for children aged less than 6 years $(30 \mu \mathrm{mol} / \mathrm{L}$ IQR $23-37$ $\mu \mathrm{mol} / \mathrm{L}) .{ }^{16}$ The surgical interventions of these 9 patients included ventriculoseptal defect repair (2/9), atrioventriculoseptal defect repair (1/9), arterial switch repair (3/9), Glenn procedure (1/9), and Fontan procedure (2/9). Patients with pulmonary hypertension had significantly longer cardiopulmonary bypass runs $(P=.04)$, significantly longer crossclamp times $(P=.034)$, and significantly more postoperative blood loss $(P<.001)$ when compared with the study population. Postoperative pulmonary hypertension did not develop in patients with plasma citrulline concentrations in excess of $37 \mu \mathrm{mol} / \mathrm{L}$ $(P=.036$, Table 3$)$.

The mean arginine concentrations were no different between patients with pulmonary hypertension receiving citrulline compared with placebo immediately postoperatively $(28 \pm 18 \mu \mathrm{mol} / \mathrm{L}$ vs $35 \pm 15 \mu \mathrm{mol} / \mathrm{L}, P=.269)$ or at other time points. Although the mean citrulline concentrations were significantly higher in patients with pulmonary hypertension receiving citrulline compared with placebo immediately postoperatively ( $42 \pm 21 \mu \mathrm{mol} / \mathrm{L}$ vs $21 \pm 8 \mu \mathrm{mol} / \mathrm{L}$, $P=.025)$, concentrations were not significantly different at other time points (Table 4).

\section{Discussion}

We found that oral citrulline supplementation safely increased postoperative plasma citrulline and arginine con- centrations compared with placebo in children after congenital heart surgery. Mean systemic blood pressure was not different between the oral citrulline and placebo groups, despite significantly different plasma citrulline concentrations. Furthermore, increased plasma citrulline concentrations were associated with a decreased risk of postoperative pulmonary hypertension.

Pulmonary hypertension can be a significant complication in children after surgical correction of their congenital heart lesions. ${ }^{4}$ Rescue therapy of postoperative pulmonary hypertension is limited to inhaled NO. Although efficacious, NO is expensive, restricted to inhaled administration, and complicated by rebound pulmonary hypertension after discontinuation. ${ }^{17}$ Developments of other therapies such as citrulline supplementation that are safe, inexpensive, and easy to administer will potentially improve postoperative outcomes.

The surgical interventions required for correction of congenital heart defects impair the production of endogenous NO, which disables pulmonary vascular homeostasis. Cardiopulmonary bypass causes pulmonary endothelial dysfunction through reduction of citrulline and arginine substrate, injury to cells secondary to complement activation and effects of oxygen free-radicals, and activation of NO synthase antagonists. ${ }^{5,6,18}$ We previously showed that cardiopulmonary bypass leads to significant decreases in both citrulline and arginine concentrations postoperatively, which do not return to baseline even by 48 hours postoperatively. ${ }^{4}$ The inability to produce endogenous NO secondary to citrulline and arginine losses in addition to dysfunction of the pulmonary endothelium may exacerbate the risk of postoperative pulmonary hypertension.

Increased pulmonary blood flow, observed with transposition of the great arteries and ventriculoseptal defects, promotes development of pulmonary hypertension through structural and functional abnormalities in the pulmonary vasculature. ${ }^{19}$ Other surgical interventions such as the Fontan and bidirectional Glenn procedures rely heavily on low pulmonary pressures for passive pulmonary blood flow. Both the sustained increased preoperative pulmonary blood flow and the deleterious effects of cardiopulmonary bypass are major contributors to the development of postoperative pulmonary hypertension. ${ }^{5}$

The expected significant decrease in plasma citrulline and arginine concentrations after cardiopulmonary bypass was prevented with the administration of oral citrulline. This effect may be secondary to both continuous production of L-arginine from citrulline and stimulation of the NO pathway in both hepatic and pulmonary tissues. Oral citrulline exhibits good bioavailability with ease of movement across cellular membranes. The cytosolic portion of the urea cycle enables localized, intracellular production of L-arginine from citrulline within the pulmonary endothelium. ${ }^{20}$ The 
TABLE 2. Patients with pulmonary artery pressure measurements after bypass, placebo $($ cit $=0$ ) and citrulline $($ cit $=1$ )

\begin{tabular}{|c|c|c|c|c|c|c|c|c|c|c|c|c|}
\hline \multirow[b]{2}{*}{ Case } & \multirow[b]{2}{*}{ Citrulline } & \multirow[b]{2}{*}{ Procedure } & \multirow{2}{*}{$\begin{array}{c}\text { Presence } \\
\text { of PHTN }\end{array}$} & \multicolumn{9}{|c|}{ Pulmonary arterial pressures $(\mathrm{mm} \mathrm{Hg})$} \\
\hline & & & & Postoperative & $6 \mathrm{~h}$ & $12 \mathrm{~h}$ & $18 \mathrm{~h}$ & $24 \mathrm{~h}$ & $30 \mathrm{~h}$ & $46 \mathrm{~h}$ & $42 \mathrm{~h}$ & $48 \mathrm{~h}$ \\
\hline 4 & 0 & BDG/Fontan & No & 19 & 12 & 15 & 16 & & & & & \\
\hline 6 & 0 & BDG/Fontan & No & 15 & 19 & 17 & 17 & 16 & 18 & 17 & 19 & 19 \\
\hline 8 & 0 & BDG/Fontan & No & 12 & 15 & 9 & 12 & 18 & & & & \\
\hline 11 & 0 & BDG/Fontan & Yes & 20 & 16 & 15 & 20 & 18 & 20 & 19 & 17 & 20 \\
\hline 15 & 0 & BDG/Fontan & No & 19 & 17 & 15 & 17 & 17 & 18 & 16 & 17 & 14 \\
\hline 24 & 0 & BDG/Fontan & No & 17 & 18 & 17 & 25 & 21 & & & & \\
\hline 27 & 0 & BDG/Fontan & No & 18 & 19 & 14 & 13 & 11 & 11 & 8 & & \\
\hline 28 & 0 & BDG/Fontan & No & 19 & 15 & 15 & 18 & 13 & 13 & & 16 & 17 \\
\hline 29 & 0 & BDG/Fontan & No & 26 & 19 & 15 & 21 & 15 & 18 & 19 & 22 & 21 \\
\hline 37 & 0 & BDG/Fontan & No & 18 & 19 & 17 & 18 & 18 & 18 & 18 & 22 & 18 \\
\hline 40 & 0 & BDG/Fontan & No & 18 & 12 & & & & & & & \\
\hline 10 & 0 & VSD/AVSD & No & 25 & & & & & & & & \\
\hline 16 & 0 & VSD/AVSD & Yes & 22 & 16 & 21 & 21 & 19 & 23 & 28 & 19 & 26 \\
\hline 35 & 0 & VSD/AVSD & Yes & 25 & 26 & & & & & & & \\
\hline 2 & 0 & Switch & Yes & 23 & 27 & 31 & 32 & 29 & 31 & 30 & 34 & 30 \\
\hline 1 & 1 & BDG/Fontan & No & 12 & 10 & 9 & 10 & 9 & & & & \\
\hline 5 & 1 & BDG/Fontan & No & 16 & 17 & 10 & 14 & 16 & 11 & 2 & 11 & \\
\hline 7 & 1 & BDG/Fontan & Yes & 21 & 19 & 22 & 29 & 22 & 27 & 22 & 35 & 30 \\
\hline 9 & 1 & BDG/Fontan & No & 22 & 15 & & 18 & 18 & 21 & 16 & 12 & 14 \\
\hline 13 & 1 & BDG/Fontan & No & 16 & 13 & 12 & 9 & 12 & & & & \\
\hline 14 & 1 & BDG/Fontan & No & 6 & 13 & 17 & 6 & & & & & \\
\hline 25 & 1 & BDG/Fontan & No & 24 & 9 & 17 & 15 & 15 & 14 & 17 & 15 & 19 \\
\hline 26 & 1 & BDG/Fontan & No & 16 & 16 & 12 & & & & & & \\
\hline 38 & 1 & BDG/Fontan & No & 17 & 16 & 15 & 17 & & & & & \\
\hline 39 & 1 & BDG/Fontan & Yes & 19 & 25 & 31 & 22 & 20 & 20 & 23 & 23 & 21 \\
\hline 20 & 1 & VSD/AVSD & No & 21 & 20 & 17 & & & & & & \\
\hline 21 & 1 & VSD/AVSD & No & 17 & 22 & 18 & 20 & & & & & \\
\hline 3 & 1 & Switch & Yes & 24 & 24 & 20 & 25 & 25 & 23 & 23 & 29 & 28 \\
\hline
\end{tabular}

$B D G$, Bidirectional Glenn; $V S D$, ventriculoseptal defect; $A V S D$, atrioventricular septal defect; PHTN, pulmonary hypertension. Pulmonary hypertension was defined as mean pulmonary arterial pressures (MPAP) of at least $25 \mathrm{mmHg}$ and/or exceeding $50 \%$ of the mean systemic artery pressure (MSAP). ${ }^{10,11}$ The citrulline group had PA pressures which trended lower than the placebo group immediately postoperative (18 \pm 5 vs $20 \pm 4, P=.127), 6$-hours postoperative (17 \pm 5 vs $18 \pm 4, P=.290)$, and 12-hours postoperative $(17 \pm 6$ vs $17 \pm 5, P=.486)$, although statistical significance could not be demonstrated in this pilot study.

TABLE 3. Low risk of pulmonary hypertension with high plasma citrulline

\begin{tabular}{cccc}
\hline $\begin{array}{l}\text { Plasma citrulline 12 h } \\
\text { postoperatively }\end{array}$ & $\begin{array}{c}\text { Pulmonary } \\
\text { hypertension } \\
\text { absent }\end{array}$ & $\begin{array}{c}\text { Pulmonary } \\
\text { hypertension } \\
\text { present }\end{array}$ & $\boldsymbol{P}$ value \\
\hline$<37 \mu \mathrm{mol} / \mathrm{L}$ & 18 & 9 & \\
$\geq 37 \mu \mathrm{mol} / \mathrm{L}$ & 12 & ${ }^{*} 0$ & .036 \\
\hline
\end{tabular}

local production of NO may be inferred from the association of high plasma citrulline concentrations and the decreased incidence of pulmonary hypertension without coexisting systemic hypotension as suggested by this study.

The risk and severity of postoperative pulmonary hypertension may vary on the basis of the type of congenital heart defect or surgical intervention required. We did not restrict enrollment to a single cardiac lesion/surgical intervention, despite the possible concern for confounders. Restricting enrollment to a homogenous population would not have appropriately addressed the treatment issues associated with the complicated disease process of pulmonary hypertension. Larger intervention trials can stratify randomization by diagnosis that may decrease concern for confounders. We randomized patients equally between the oral citrulline and placebo groups without stratification because of the small sample size. Consequently, all 3 patients undergoing the Norwood I procedure were randomly assigned to the citrulline group. This imbalance had a risk of favoring the null hypothesis because these patients historically have more complicated postoperative courses associated with extremely low cardiac output states. However, these patients demonstrated a relatively uncomplicated 48 -hour postoperative course, which presumably permitted adequate absorption of citrulline and appropriate assessment of its clinical effects. 
TABLE 4. Characteristics of patients with pulmonary hypertension diagnosis

\begin{tabular}{|c|c|c|c|c|c|c|c|c|c|c|c|c|c|c|c|}
\hline \multirow[b]{2}{*}{ Case } & \multirow[b]{2}{*}{ Citrulline } & \multirow[b]{2}{*}{ Age } & \multirow[b]{2}{*}{ Procedure } & \multicolumn{2}{|c|}{$\begin{array}{l}\text { Method of } \\
\text { PHTN } \\
\text { diagnosis }\end{array}$} & \multicolumn{5}{|c|}{ Plasma arginine $\mu \mathrm{mol} / \mathrm{L}$} & \multicolumn{5}{|c|}{ Plasma citrulline $\mu \mathrm{mol} / \mathrm{L}$} \\
\hline & & & & Echo & PAP & Pre & Post & $12 \mathrm{~h}$ & $24 \mathrm{~h}$ & $48 \mathrm{~h}$ & Pre & Post & $12 \mathrm{~h}$ & $24 \mathrm{~h}$ & $48 \mathrm{~h}$ \\
\hline 2 & Placebo & $<1 \mathrm{mo}$ & Switch & & Yes & 104 & 52 & 24 & 13 & 56 & 15 & 9 & 7 & 5 & 4 \\
\hline 31 & Placebo & $<1 \mathrm{mo}$ & Switch & Yes & & 56 & 36 & 44 & 45 & 213 & 23 & 12 & 10 & 9 & 17 \\
\hline 16 & Placebo & $4 \mathrm{mo}$ & AVSD & & Yes & 39 & 8 & 13 & 5 & 4 & 47 & 26 & 31 & & 13 \\
\hline 35 & Placebo & $5 \mathrm{mo}$ & VSD & Yes & & 70 & 45 & 33 & 27 & 33 & 40 & 24 & 28 & 16 & 10 \\
\hline 36 & Placebo & $8 \mathrm{mo}$ & VSD & Yes & & 22 & 37 & 5 & 6 & 4 & 18 & 24 & 12 & 11 & 12 \\
\hline 11 & Placebo & $8 \mathrm{mo}$ & $\mathrm{BDG}$ & & Yes & 30 & 34 & 13 & 19 & 11 & 41 & 29 & 29 & 26 & 16 \\
\hline 3 & Citrulline & $<1 \mathrm{mo}$ & Switch & & Yes & 24 & 41 & 11 & 8 & 18 & 27 & 66 & 17 & 15 & 17 \\
\hline 7 & Citrulline & $29 \mathrm{mo}$ & Fontan & & Yes & 57 & 36 & 79 & & & 36 & 29 & 19 & & \\
\hline 39 & Citrulline & $25 \mathrm{mo}$ & Fontan & & Yes & 33 & 7 & 15 & 13 & 8 & 24 & 32 & 18 & 6 & 6 \\
\hline
\end{tabular}

PHTN, Pulmonary hypertension; Echo, echocardiography; PAP, pulmonary arterial pressure; AVSD, atrioventricular septal defect; VSD, ventriculoseptal defect; $B D G$, bidirectional Glenn. The median citrulline concentration was significantly higher in the citrulline group versus placebo immediately postoperative ( $36 \mathrm{umol} / \mathrm{L}$ vs $26 \mathrm{umol} / \mathrm{L}, P=.012$ ) and at 12 -hours postoperative $(37 \mathrm{umol} / \mathrm{L} \mathrm{vs} 20 \mathrm{umol} / \mathrm{L}, P=.015)$. ${ }^{*}$ Patients with plasma citrulline concentrations in excess of $37 \mathrm{umol} / \mathrm{L}$, whether naturally occurring or with citrulline supplementation, did not develop postoperative pulmonary hypertension $(P=.036)$.

This pilot study demonstrated that an oral citrulline regimen used in children with urea cycle defects can also be safely administered to children undergoing cardiopulmonary bypass with subsequent elevations in plasma citrulline concentrations. We were able to further demonstrate an association between citrulline concentrations and occurrence of postoperative pulmonary hypertension. Two limitations in definitively describing this relationship included the method of pulmonary hypertension diagnosis and the citrulline-dosing regimen. Our study protocol limited interference of routine postoperative care, and therefore pulmonary arterial lines were not mandated. Diagnosis of postoperative pulmonary hypertension in patients without direct pulmonary pressure measurement was completed by echocardiography, which has known limitations.

Few patients receiving oral citrulline did not demonstrate the significant increase in plasma citrulline concentration, and consequently were at risk for postoperative pulmonary hypertension. Risk factors for development of pulmonary hypertension in this study population included significantly longer cardiopulmonary bypass runs, longer crossclamp times, and more postoperative blood loss. Inability to overcome pulmonary endothelial dysfunction because of ongoing citrulline losses after bypass may have exacerbated the risk of developing pulmonary hypertension in these patients. We expect that higher doses of oral citrulline will achieve levels in much greater excess than $37 \mu \mathrm{mol} / \mathrm{L}$, and that with consistently elevated citrulline concentrations pulmonary hypertension may be prevented. With this pilot study, we targeted those plasma concentrations that are associated with a decreased risk of pulmonary hypertension. Furthermore, the safety data and plasma concentrations achieved with oral citrulline enabled us to begin pharmaco- kinetic studies of intravenous citrulline and its future use in the treatment of pulmonary hypertension.

\section{Conclusion}

Oral citrulline supplementation safely increased plasma concentrations of both citrulline and arginine compared with placebo. Elevations in plasma citrulline concentrations above age-specific norms, whether naturally occurring or with citrulline supplementation, were associated with a decreased risk of postoperative pulmonary hypertension. Therefore, aggressive oral citrulline supplementation or future use of intravenous citrulline, resulting in consistent citrulline concentrations in excess of $37 \mu \mathrm{mol} / \mathrm{L}$, may prevent postoperative pulmonary hypertension. ${ }^{7}$

\section{References}

1. Wheller J, George BL, Mulder DG, Jarmakani JM. Diagnosis and management of postoperative pulmonary hypertensive crisis. Circulation. 1979;60:1640-4.

2. Burrows FA, Klink JR, Rabinovitch M, Bohn DJ. Pulmonary hypertension in children: perioperative management. Can Anaesth Soc J. 1986;33:606-28.

3. Moncada S, Higgs A. Mechanisms of disease: the L-arginine-nitric oxide pathway. N Engl J Med. 1993;329:2002-12.

4. Barr FE, Beverley H, VanHook K, Cermak E, Christian K, Drinkwater $\mathrm{D}$, et al. Effect of cardiopulmonary bypass on urea cycle intermediates and nitric oxide levels after congenital heart surgery. J Pediatr. 2003; 142:26-30.

5. Schulze-Neick I, Penny DJ, Rigby ML, Morgan C, Kelleher A, Collins $\mathrm{P}$, et al. L-arginine and substance $\mathrm{P}$ reverse the pulmonary endothelial dysfunction caused by congenital heart surgery. Circulation. 1999; 100:749-55

6. Schulze-Neick I, Li J, Penny DJ, Redington AN. Pulmonary vascular resistance after cardiopulmonary bypass in infants: effect on postoperative recovery. J Thorac Cardiovasc Surg. 2001;121:1033-9.

7. Badesch DB, Abman SH, Ahearn GS, Barst RJ, McCrory DC, Simonneau G, et al. Diagnosis and the management of pulmonary 
arterial hypertension: ACCP evidence-based clinical practice guidelines. Chest. 2004;126:35S-62S.

8. Harrison DG. Cellular and molecular mechanisms of endothelial cell dysfunction. J Clin Invest. 1997;100:2153-7.

9. Kuhn KP, Harris PA, Cunningham GR, Robbins IM, Lawson WE, Summar ML, et al. Oral citrulline effectively elevates plasma arginine levels for 24 hours in normal volunteers. Circulation. 2002; 106:II-339.

10. Russell IAM, Zwass MS, Fineman JR, Balea M, Rouine-Rapp K, Brook M, et al. The effects of inhaled nitric oxide on postoperative pulmonary hypertension in infants and children undergoing surgical repair of congenital heart disease. Anesth Anal. 1998;87:46-51.

11. Rich S, Dantzker DR, Ayres SM, Bergofsky EH, Brundage BH, Detre $\mathrm{KM}$, et al. Primary pulmonary hypertension. A national prospective study. Ann Intern Med. 1987;107:216-23.

12. Berger M, Haimowitz A, Van Tosh A, Berdoff RL, Goldberg E. Quantitative assessment of pulmonary hypertension in patients with tricuspid regurgitation using continuous wave Doppler ultrasound. J Am Coll Cardiol. 1985;6:359-65.

13. Kim NHS. Diagnosis and evaluation of the patient with pulmonary hypertension. Cardiol Clin. 2004;22:367-73.
14. Brusilow SW, Valle DL, Batshaw M. New pathways of nitrogen excretion in inborn errors of urea synthesis. Lancet. 1979;2:452-4.

15. Batshaw ML, Brusilow S, Waber L, Blom W, Brubakk AM, Burton BK, et al. Treatment of inborn errors of urea synthesis: Activation of alternative pathways of waste nitrogen synthesis and excretion. $N$ Engl J Med. 1982;306:1387-92.

16. Lepage N, McDonald N, Dallaire L, Lambert M. Age-specific distribution of plasma amino acid concentrations in a healthy pediatric population. Clin Chem. 1997;43:2397-402.

17. Miller OI, Celermajer DS, Deanfield JE, Macrae DJ. Very low dose inhaled nitric oxide: a selective pulmonary vasodilator after surgery for congenital heart disease. J Thorac Cardiovasc Surg. 1994;108: 487-94.

18. Mehta S, Stewart DJ, Langleben D, Levy RD. Short-term pulmonary vasodilation with L-arginine in pulmonary hypertension. Circulation. 1995;92:1539-45.

19. Steinhorn RH, Fineman JR. The pathophysiology of pulmonary hypertension in congenital heart disease. Artif Organs. 1999;23: 970-4.

20. Zobel G, Gamillscheg A, Schwinger W, Berger J, Urlesberger B, Dacar D, et al. Inhaled nitric oxide in infants and children after open heart surgery. J Cardiovasc Surg. 1998;39:79-86. 